\title{
Psychological wellbeing among carers of people with spinal cord injury: a preliminary investigation from South India
}

\author{
C Manigandan ${ }^{1}$, B Saravanan*,2, A Macaden ${ }^{1}$, L Gopalan ${ }^{1}$, G Tharion ${ }^{1,3}$ and S Bhattacharji ${ }^{1}$ \\ ${ }^{1}$ Department of Physical Medicine and Rehabilitation, Christian Medical College and Hospitals, Vellore 632004, \\ India; ${ }^{2}$ Department of Psychiatry, Christian Medical College, Vellore 632002, India
}

\begin{abstract}
Study design: A cross-sectional study that assessed people with spinal cord injury (SCI) and their carers who attended the 3-day health care program.

Objectives: The study examined the nature and prevalence of the factors associated with psychological morbidity among carers of people with SCI.

Setting: A community reintegrated population of persons with SCI and their carers attended the 3-day program in the Department of Physical Medicine and Rehabilitation, Christian Medical College Hospitals, Vellore, South India.

Methods: Thirty-eight people with SCI and their carers participated in this cross-sectional study.

Results: Thirty $(78.9 \%)$ carers of people with SCI were psychologically distressed. While carers were distressed, they were not significantly depressed. Educational level of carers and suicidal behavior of people with SCI were significantly associated with psychological distress. Conclusion: The findings of this study suggest that health care workers should have a high index of suspicion of psychological morbidity, in carers of people with SCI. Identification of risk factors may lead to useful target interventions.
\end{abstract}

Sponsorship: Nil.

Spinal Cord (2000) 38, 559-562

Keywords: spinal cord injury; psychological wellbeing; psychological morbidity; carers; depression

\section{Introduction}

The result of permanent loss of movement is a catastrophe for people with spinal cord injury (SCI). Recovery from SCI requires substantial coping by the patient and their carers. ${ }^{1,2}$ Carers experience significant burden, especially in the social role functioning and adjustment to the ongoing recovery process. ${ }^{3,4}$ This burden, if excessive, may lead to emotional break down among carers. Despite the last few decades having witnessed an increase in literature regarding psychological reaction to people with $\mathrm{SCI}^{5-7}$, there is a paucity of studies on the psychological wellbeing of the carers of people with SCI. However, few studies had looked in to caregiving and social support in people with SCI, yet many problems remain ${ }^{8-11}$ Inadequate explication of social support, potential spuriousness and reverse causation, threats to statistical conclusion validity, and lack of generalization were found. ${ }^{12}$ Theoretical approaches to the understanding of psychological adjustment have recently experienced a re-examination

*Correspondence: B Saravanan, Department of Psychiatry, Christian Medical College, Vellore 632002, India

${ }^{3}$ Current address: Princess Royal Spinal Injury Centre, Northern General Hospital, Sheffield S5 AU, UK which seriously questions the traditional 'stage theory' of adjustment. Despite limited empirical validation at best, the stage theory has not only enjoyed an unchallenged popularity amongst rehabilitation professionals but this tendency often extended to research personnel who tended to overestimate depression, anxiety and social discomfort, while underestimating the optimism of their SCI people and their carers. ${ }^{13,14}$ This study aimed to address these controversies by examining the nature and prevalence of factors associated with psychological morbidity among carers of people with SCI from a community reintegrated population.

\section{Materials and methods}

\section{Subjects}

The study was carried out in the Department of Physical Medicine and Rehabilitation, Christian Medical College, Vellore. The department is a tertiary referral center for people with SCI. People with SCI are admitted and treated as in-patients for 2-3 months. These people are followed-up regularly as 
out-patients. People who are successfully rehabilitated and living within a distance of $100 \mathrm{kms}$ from the center are invited by the department to take part in a 3 day program of health care screening and check-up and cultural activities.

\section{Materials}

The sample for this study consisted of 60 people with SCI and their carers (those who look after people with SCI most of the time) who participated in this 3 day program. Individuals who had come with carers aged less than 18 years and those carers who are not currently staying with SCI people were excluded.

\section{Socio-demographic and health status assessment of carers}

The following methods were used to assess sociodemographic and health status:

(a) A specially designed proforma to assess sociodemographic characteristics, relationship of carers to the patient, health status of carers (which included number of previous and recent consultations with the family physician, co-morbid medical illness, use of psychotropic medications and other substances).

(b) The Tamil version of 12-item General Health Questionnaire (GHQ-12), a measure of current psychological distress. The $2 / 3$ threshold was used to identify possible cases of psychological morbidity. This threshold has a sensitivity of $83.7 \%$ and a specificity of $79.0 \%$ which has been validated in the medical population ${ }^{15,16}$ who attended a primary health center in Vellore.

(c) The Hospital Anxiety and Depression scale (HAD), a measure of state of anxiety and depression, a selfrating instrument. ${ }^{17}$

Functional Independence Measure of subjects with SCI Functional Independence Measure (FIM)-to assess the level of independence ${ }^{18}$ of people with SCI was employed. The FIM consists of 18 items organized under six categories of function. The categories include self-care activities (eating, grooming, bathing, upper and lower body dressing, and toileting); sphincter control (bowel and bladder management); mobility (transfers to toilet, bed, chair, bath); locomotion (walking, wheelchair, stairs); communication (comprehension, expression); and social cognition. The maximum score is 126 points. ${ }^{19}$ FIM reflects an appreciation of the multidimensional nature of functional independence.

Problem behaviors of people with SCI and social support of carers

Problem behaviors of people with SCI (hostility, assaultive behaviors, unco-operativeness and suicidal behaviors) were recorded using a problem behavior check-list. The availability of social support for the carers were also recorded.

\section{Results}

Thirty-eight people with SCI and their caregivers, of 60 individuals who came for the 3 day program, fulfilled the inclusion criteria and they were recruited. Table 1 shows the distribution of individuals who participated in the study. The difference in age and gender of subjects who refused consent and those who were recruited was not statistically significant. Table 2 shows the descriptive characteristics of people with SCI and their carers. The majority of the individuals were male while a significant proportion of the carers were women. A significant proportion of carers were spouses.

\section{Severity of SCI among people}

Table 3 shows the distribution of average scores among FIM scales. Twenty-eight $(73 \%)$ of people with SCI were completely independent; nine $(23 \%)$ were moderately dependent and one (2.6\%) was completely dependent. The mean FIM score was 97.34 $(\mathrm{SD}=22.95$; range $=37-121)$.

Table 1 Distribution of carers participating in the study

\begin{tabular}{lc}
\hline Category & $\begin{array}{c}\text { Number of } \\
\text { subjects }\end{array}$ \\
\hline Identified population & 60 \\
Exclusion criteria & \\
(a) carers aged less than 18 & 5 \\
(b) carers who are not currently staying & 12 \\
$\quad$ with people with SCI & 43 \\
Met entry criteria & 38 \\
(a) willingness to participate & 5 \\
(b) not willing to participate & \\
\hline
\end{tabular}

Table 2 Descriptive characteristics of people with SCI and their carers

\begin{tabular}{|c|c|c|}
\hline Category & $\begin{array}{c}\text { People with } \\
\text { SCI }\end{array}$ & Carers \\
\hline Male & 37 & 11 \\
\hline Female & 1 & 27 \\
\hline Age (mean; SD) & $33.23 ; 10.87$ & $36.36 ; 11.25$ \\
\hline $\begin{array}{l}\text { Duration of injury in } \\
\text { months (mean; SD) }\end{array}$ & $86.55 ; 52.99$ & \\
\hline \multicolumn{3}{|c|}{ Relationship to people with } \\
\hline \multicolumn{3}{|c|}{ SCI $(n ; \%)$} \\
\hline (a) Spouse & & $29 ; \quad 52.6 \%$ \\
\hline (b) Parent & & $11 ; \quad 28.9 \%$ \\
\hline (c) Son & & $1 ; \quad 2.6 \%$ \\
\hline (d) Siblings & & $6 ; \quad 15.8 \%$ \\
\hline
\end{tabular}


Carers psychological health

Table 4 shows the distribution of GHQ scores and HAD scores. Using the $2 / 3$ threshold, approximately $79 \%$ of the carers were distinctly psychologically distressed. Carers mean GHQ scores who were probable or definite cases (Table 4) differed from comparable community based data reported for the medical population who attended a primary health center in Vellore. ${ }^{15,16}$ In the community based study the mean GHQ score of 2.34 (SD 2.6) was very much lower, while $43 \%(n=143)$ of all respondents scored 2 or more compared to $78.9(n=30)$ in the present study. While general psychological morbidity scores were high, Hospital Anxiety and Depression Rating Scale (HAD) scores were not. Using the cut-off score (score of $11-21$ as significant anxiety and depression) $26.3 \%$ and $18.4 \%$ had significant anxiety and depression respectively.

Factors associated with carers psychological distress Carers low-education (2-tail significance 0.02 95\% CI $5.18,0.61)$, suicidal (2-tail significance $0.001,95 \%$ CI $1.86,6.03$ ) and aggressive behavior (2-tail significance $0.04,95 \%$ CI $0.15,6.73$ ) of people with SCI, were found to be significantly associated with carers psychological distress on univariate analysis. Suicidal behavior of people with SCI and carers low

Table 3 Distribution of average scores among FIM scales

\begin{tabular}{|c|c|c|c|}
\hline \multirow[b]{2}{*}{ FIM Subscales } & \multicolumn{3}{|c|}{ Level of independence } \\
\hline & $\begin{array}{l}\text { Independent } \\
(\mathrm{n}, \%)\end{array}$ & $\begin{array}{c}\text { Complete } \\
\text { dependence } \\
(\mathrm{n}, \%)\end{array}$ & $\begin{array}{c}\text { Moderate } \\
\text { dependence } \\
(\mathrm{n}, \%)\end{array}$ \\
\hline Con & $0(0.0)$ & $1(2.6)$ & 37 (97.4) \\
\hline Locomotion & $11(28.9)$ & $15(39.5)$ & 12 (31.6) \\
\hline Mobility & $10(26.3)$ & $7(18.4)$ & $21(55.3)$ \\
\hline Self-care & $2(5.3)$ & $4(10.5)$ & $32(84.2)$ \\
\hline Sphincter control & $6(15.8)$ & $11(28.9)$ & $21(55.3)$ \\
\hline
\end{tabular}

Table 4 Distribution of GHQ scores and mean HAD scores

\begin{tabular}{lc}
\hline Category & Scores \\
\hline GHQ mean (SD, range) & $6.21(3.53,0-12)$ \\
GHQ $<2(\mathrm{n})$ & $8(21.1 \%)$ \\
GHQ $>/=3(\mathrm{n})$ & $30(78.9 \%)$ \\
HAD-D mean $(\mathrm{SD}$, range) & $8.4(3.1,0-15)$ \\
HAD-D cut-off & \\
$0-7$ no depression & $13(34.2 \%)$ \\
$8-10$ borderline & $18(47.4 \%)$ \\
$11-21$ significant depression & $7(18.4 \%)$ \\
HAD-A mean $(\mathrm{SD}$, range) & $7.4(4.7,0-20)$ \\
HAD-A cut-off & $17(44.7 \%)$ \\
$0-7$ no anxiety & $11(28.9 \%)$ \\
$8-10$ borderline & $10(26.3 \%)$ \\
$11-21$ significant anxiety &
\end{tabular}

education remained significantly associated with psychological distress even after adjusting for the other variables using multiple linear regression $(\mathrm{T}=3.34$ and 3.16). Assaultive behavior of people with SCI which was significantly associated in univariate analysis (2-tail significance 0.04, 95\% CI $0.15,6.73$ ) was not significantly related after the multivariate procedure. The following factors were also not significantly associated with carers psychological distress: Being a spouse; SCI severity; hostility; uncooperativeness; and socio economic status.

\section{Discussion}

The findings suggest that a significant proportion of carers do suffer from psychological distress. Carers mean GHQ scores who were probable or definite cases was much higher when compared with community based data reported for the medical population who attended a primary health center in Vellore. ${ }^{15,16}$

Low education of the carers and suicidal behavior were significant risk factors for psychological distress. Limited intellectual resources to cope has a relationship between psychological resources of sense of control and caregiver mastery. ${ }^{20}$ Stereotypes of Indian religiosity have long focused on passivity and external locus of control, inferred from beliefs in fate and karma. While such ideas may be associated with the failure to make use of available help, a closer look from this socio-cultural background suggests that these carers in fact bear the weight of moral responsibility as well, akin to guilt, which increases their psychological distress. ${ }^{21,22}$ Although karma specifies ideas of cause and effect in the context of moral economy, the context in which carers generally felt distress was the unpredictability of events. Emotional distress associated with suicidal behavior impair the carers ability to cope with stress and lead to further worsening of psychological distress. De facto interventions have been offered to SCI people with high suicidal ideation on an on-going basis. In fact, there is a liaison psychiatric team which consists of mental health professionals and community based health workers which functions at the community base.

There were also several negative findings of interest. Firstly, while carers were psychologically distressed, they were not significantly depressed or anxious. This suggests that family members caring for people with SCI are more prone to suffer general psychological distress but are not distinctly depressed or anxious. They endure an impaired quality of life, particularly if stressed by the suicidal behavior of the SCI people.

Secondly, the majority of people with SCI who attended the program were functionally independent. This may partly explain the lack of correlation between Functional Independence Measure scores and carers psychological distress. For testing this correlation, persons with diverse scores on the Functional Independence Measure scale will be required. 
The findings of this study suggest that rehabilitation teams should have a high index of suspicion of psychological morbidity in carers of people with SCI. Future research in this area has to focus on the cultural and clinical context to identify locally meaningful categories and elaborating insider's point of view (the emic approach). This technique studies the relationship between culturally defined experience and professionally defined outcomes. As the majority of the subjects in this study were Hindus, some of the cultural explanations regarding illness were focused on fate, karma passivity and external locus of control. This culturally defined experience may be associated with the failure to make use of available help. So, when cultural meanings and their emotional implications outweigh the burden of disability early in its course, health education should be done without 'debunking' their views. This will reduce their psychological distress and improve the quality of life of patients and their families.

\section{Acknowledgments}

We are grateful to Professor KS Jacob for his advice, encouragement and valuable comments on the earlier drafts of the manuscript.

\section{References}

1 Killen JM. Role stabilization in families after spinal cord injury. Rehabil Nurs 1990; 15: 19-21.

2 Sullivan J. Individual and family responses to acute spinal cord injury. Crit Care Nurs Clin North Am 1990; 2: 407-414.

3 Stambrook $\mathrm{M}$ et al. Social role functioning following spinal cord injury. Paraplegia 1991; 29: $318-323$.

4 Rintala DH, Young ME, Spencer JC, Bates PS. Family relationships and adaptation to spinal cord injury: a qualitative study. Rehabil Nurs 1996; 21: 67-74.

5 Craig AR et al. Psychological consequences of spinal injury: A review of the literature. Australian New Zealand $J$ Psychiatry 1990; 24: $418-425$.
6 Scivoletto G, Petrelli A, DiLucente L, Castellano V. Psychological investigation of spinal cord injury patients. Spinal Cord 1997; 35: 516-520.

7 Hancock KM et al. Anxiety and depression over the first year of spinal cord injury: a longitudinal study. Paraplegia 1993; 31: $349-357$.

8 Decker SD et al. Determinants of well-being in primary caregivers of spinal cord injured persons. Rehabil Nurs 1989; 14: $6-8$.

9 Mackelprang RW, Hepworth DH. Ecological factors in rehabilitation of patients with severe spinal cord injuries. $J$ Soc Work Health Care 1987; 13: 23-38.

10 Delargy M et al. Quadriplegic care: an assessment of the impact on the carer. Int Disability Studies 1988; 10: 145-147.

11 Rosenbaum M, Najenson T. Changes in life patterns and symptoms of low mood as reported by wives of severely brain injured soldiers. J Consulting Clin Psych 1976; 44: 881-888.

12 Vrabec NJ. Literature review of social support and caregiver burden, 1980 to 1995. Image J Nurs Sch 1997; 29: 383-388.

13 Ernst FA. Contrasting perceptions of distress by research personnel and their spinal cord injured subjects. Am J Phys Med 1987; 66: 6-8.

14 Buckelew SP et al. Adjustment to spinal cord injury: stage theory revisited. Paraplegia 1991; 29: $125-130$.

15 Kuruvilla A et al. The validation of the Tamil version of the 12 item General Health Questionnaire. Indian J Psychiatry 1999; 41: $217-221$.

16 Pothen $\mathrm{M}$ et al. Common mental disorders in Vellore, South India: Nature, prevalence and risk factors. Indian J Psychiatry 1999; 41 (Supp): 59

17 Zigmond AS, Snaith RP. The hospital anxiety and depression scale (HAD), Acta Psychiatr Scand 1983; 67: 361 - 370.

18 Roth E et al. Functional assessment in spinal cord injury: A comparison of the modified Barthel index and the 'adapted' functional independence measure. Clin Rehabil 1990; 4: 277-285.

19 Hamilton BB et al. Interagreement of the seven level Functional Independence Measure (FIM). Arch Phys Med Rehabil 1991; 7: 790.

20 Miller B et al. Race control, mastery and caregiver distress. $J$ Gerentol B Psychol Sci Soc Sci 1995; 50: 374-382.

$21 \mathrm{Babb}$ LA. Destiny and responsibility: karma in popular Hinduism. In: (eds). Keyes CF, Daniel EG (eds) Karma: An Anthropological Inquiry. University of California Press: Berkeley, pp $163-181$

22 Weiss MG, Kleinman AK. Depression in cross cultural perspective: developing a culturally informed model. In: Dasen P, Sartorius N, Berry J (eds). Psychology, Culture and Health: Towards Application. Sage: Beverly Hills, pp 179-206. 